\title{
Distribusi Famili Zingiberaceae Pada Ketinggian Yang Berbeda Di Kabupaten Semarang
}

\author{
Hanif Maya Sari, Sri Utami, Erry Wiryani, Murningsih dan Lilih Khotim Perwati \\ Laboratorium Ekologi dan Biosistematik Jurusan Biologi FSM Undip
}

\begin{abstract}
Abstrak
Zingiberaceae merupakan tumbuhan obat yang menjadi komoditas unggulan. Kabupaten Semarang merupakan salah satu sentra distribusi Zingeberaceae. Faktor lingkungan yang mempengaruhi distribusi Zingiberaceae adalah ketinggian tempat, kelembaban, suhu udara, $\mathrm{pH}$ tanah, dan intensitas cahaya. Tujuan penelitian ini adalah untuk mengkaji jenis-jenis tumbuhan anggota Zingeberaceae, distribusi Zingiberaceae, dan pengaruh ketinggian tempat terhadap distribusi Zingiberaceae di Kabupaten Semarang. Penelitian dilaksanakan pada bulan September sampai November 2010. Pengambilan sampel tumbuhan famili Zingiberaceae dilakukan di lima kecamatan Kabupaten yang memiliki ketinggian berbeda. Analisis data dilakukan dengan menggunakan indeks nilai penting, derajat konstansi, dan analisis korelasi pengaruh ketinggian tempat terhadap distribusi Zingiberaceae. Dari hasil penelitian didapatkan 12 jenis dan satu varietas tumbuhan anggota Zingeberaceae di Kabupaten Semarang. Jenis yang mempunyai nilai penting tinggi adalah Curcuma domestica (kunyit) dan Amomun cardomomum (kapulaga). Jenis yang mempunyai distribusi paling luas di Kabupaten Semarang adalah Amomum cardomomum, Curcuma xanthorrhiza, Curcuma domestica, Zingiber americans dan Zingiber officinale.
\end{abstract}

Kata kunci : Distribusi, Zingiberaceae, Ketinggian Tempat, Kabupaten Semarang.

\section{PENDAHULUAN}

Zingiberaceae merupakan tanaman yang mengandung zat kimia (minyak atsiri). Tumbuhan ini sering dimanfaatkan sebagai bumbu masak, obat, tanaman hias, bahan kosmetik, bahan minuman, dan sebagainya. Sebagian besar jenis tumbuhan anggota Zingiberaceae dimanfaatkan sebagai tanaman obat. Permintaan akan jenis tanaman obat famili Zingeberaceae meningkat secara signifikan karena peningkatan kebutuhan tanaman obat dari masyarakat. Tanaman obat ini digunakan untuk industri jamu maupun farmasi. Propinsi Jawa Tengah merupakan propinsi ketiga terbesar yang memiliki industri jamu di Indonesia.

Menurut Kuntorini (2005), ada tiga anggota Zingiberaceae yang sering dimanfaatkan oleh masyarakat sebagai tanaman obat yaitu kunyit (Curcuma domestica), jahe (Zingiber officinale) dan kencur (Kaempferia galanga). Joy et al., (1998), menambahkan genus dari famili Zingiberaceae yang sering dimanfaatkan sebagai tanaman obat adalah Curcuma, Kaempferia, Hedychium, Amomum, Zingiber, Alpinia, Elettaria dan Costus.

Anggota famili ini sering ditemukan di kawasan hutan tropis, terutama Indo-Malaya. Zingiberaceae belum diketahui secara pasti berapa jumlah spesiesnya. Menurut Pandey (2003) dalam Siagian (2009), terdapat kurang lebih 50\% dari total genus famili Zingiberaceae yang ditemukan di hutan tropis. Derlin dan Larsen (2000) mengemukakan di Asia terdapat 20 genus dan 216 jenis. Vareasi jenis terlihat dari perbedaan organ generatifnya. Zingiberaceae dapat hidup dari dataran rendah sampai ketinggian 2000 meter di atas permukaan laut terutama daerah dengan curah hujan yang tinggi.

Kabupaten Semarang merupakan salah satu kabupaten dari 16 kabupaten di Jawa Tengah yang berpotensi untuk pengembangan tanaman obat. Tanaman obat dari kelompok rimpang yang cukup potensial dikembangkan sebagai komoditi unggulan yaitu jahe, kunyit, kencur, temulawak, laos, kunyit putih dan lempuyang (Direktorat Jendral Hortikultura, 2006).

Kabupaten Semarang memiliki luas wilayah 95.020,674 hektar dan berada pada ketinggian 318 hingga 1450 mdpl. Desa Candirejo di Kecamatan Ungaran Barat merupakan desa dengan ketinggian terendah, sedangkan Desa Batur di Kecamatan Getasan merupakan wilayah desa dengan ketinggian tertinggi. Suhu udara rata-rata di Kabupaten Semarang dapat dikatakan sejuk. Ratarata curah hujan di wilayah Kabupaten Semarang 
pada tahun $20081.622 \mathrm{~mm}$. Kecamatan Pringapus merupakan kecamatan dengan curah hujan tertinggi $(3.155 \mathrm{~mm})$ dan Kecamatan Suruh bercurah hujan terendah $798 \mathrm{~mm}$ (Badan Pusat Statistik Kabupaten Semarang, 2009).

Distribusi suatu jenis tanaman pada suatu komunitas dapat digambarkan melalui frekuensinya. Semakin sering suatu jenis terdapat pada suatu komunitas berarti semakin besar distribusinya, Good (1953) dalam Poernamasari (1989). Odum (1993) mengemukakan bahwa faktor lingkungan yang penting sebagai faktor pembatas yang mempengaruhi distribusi suatu organisme adalah suhu, kelembaban, keadaan tanah, air, sinar matahari, ketinggian tempat dan lain-lain

Kabupaten Semarang merupakan salah satu sentra distribusi Zingeberaceae. Letak geografis Kabupaten Semarang yang mempunyai ketinggian tempat berbeda-beda akan menyebabkan distribusi jenis anggota famili Zingeberaceae akan berbeda. Oleh karena itu perlu kiranya dilakukan penelitian mengenai jenis-jenis tumbuhan famili Zingeberaceae dan distribusinya di Kabupaten Semarang. Hasil penelitian ini diharapkan akan menambah informasi untuk pengembangan jenisjenis tanaman famili Zingeberaceae agar lebih maksimal.

\section{BAHAN DAN METODE}

Penelitian dilakukan di Kabupaten Semarang pada bulan September sampai November 2010.

Alat dan bahan: meteran, tali simpul, kamera, luxmeter, higrometer, termometer udara, termometer tanah, pH meter, pasak, GPS (Global Position System), dan alat tulis, sasak herbarium, kertas koran dan alkohol $70 \%$.

Pengambilan sampel dilakukan di lima stasiun yang mempunyai ketinggian tempat berbeda (Tabel 1)
Tabel 1. Stasiun pengambilan sampel di Kabupaten Semarang

\begin{tabular}{llc}
\hline No & \multicolumn{1}{c}{ Stasiun } & $\begin{array}{c}\text { Ketinggian tempat } \\
(\mathrm{mdpl})\end{array}$ \\
\hline 1 & Kec. Ungaran & $<500$ \\
\hline 2 & Kec. Bergas & $500-750$ \\
\hline 3 & Kec. Tengaran & $750-1000$ \\
\hline 4 & Kec. & $1000-1250$ \\
& Somowono & \\
\hline 5 & Kec. Getasan & $>1250$ \\
\hline
\end{tabular}

Pada masing-masing stasiun diambil 5 plot secara acak dengan ukuran plot $5 \mathrm{~m}$ x $5 \mathrm{~m}$. Pada setiap plot dilakukan pencatatan jenis-jenis tumbuhan anggota famili Zingeberaceae, dihitung jumlah individu setiap jenisnya dan diukur diameter tajuknya (cover). Jenis-jenis tumbuhan yang belum tahu namanya diambil sampelnya dan dibuat herbarium untuk diidentifikasi di laboratorium ( Backer and Brink, 1968 dan Heyne, 1987). Setiap stasiun dilakukan pengukuran faktor lingkungan meliputi: kelembaban, suhu udara, $\mathrm{pH}$ tanah dan intensitas cahaya.

Analisis data:

Data yang diperoleh dianalisis dengan menghitung nilai penting masing-masing jenis tumbuhan yang ditemukan di setiap stasiun penelitian (Dombois and Ellenberg, 1974):

Kerapatan $=\frac{\text { jumlah individu suatu jenis }}{\text { luas seluruh petak contoh }}$

KerapatanRelatif $(\mathrm{KR})=$

$\frac{\text { nilai kerapatan suatu jenis }}{\text { total kerapatan seluruh jenis }} \times 100 \%$

Dominansi $=\frac{\text { luas penutupan suatu jenis }}{\text { luas seluruh petak contoh }}$

Dominasi Relatif $(\mathrm{DR})=$

$\frac{\text { nilai dominansi suatu jenis }}{\text { total dominansi seluruh jenis }} \times 100 \%$ 
Frekuensi $=$

jumlah petak contoh ditemukan suatu jenis jumlah seluruh petak contoh

Frekuensi Relatif $(\mathrm{FR}) \quad=$ $\frac{\text { nilai frekuensi suatu jenis }}{\text { total frekuensi seluruh jenis }} \times 100 \%$

Indeks Nilai Penting $=$ Kerapatan rel + Dominansi rel + Frekkuensi rel
Untuk mengetahui distribusi tumbuhan Zingeberaceae dilakukan dengan menghitung derajat konstansi masing-masing jenisnya. Dilakukan pengukuran faktor lingkungan pada masing-masimg stasiun yang meliputi : suhu tanah, suhu udara, kelembaban udara, $\mathrm{pH}$ tanah dan ketinggian tempat.

\section{HASIL DAN PEMBAHASAN}

Berdasarkan hasil penelitian yang telah dilakukan di Kabupaten Semarang ditemukan 12 jenis tumbuhan dan satu varietas anggota famili Zingiberaceae Jenis-jenis tersebut termasuk dalam 6 genus, yaitu Alpinia, Amomum, Costus, Curcuma, Kaempferia, dan Zingiber (Tabel 2).

Tabel 2. Jenis-jenis tumbuhan dan Indeks Nilai Penting (\%) famili Zingeberaceae di Kabupaten Semarang

\begin{tabular}{llllllll}
\hline No & Nama ilmiah & Nama lokal & St.1 & St.2 & St.3 & St.4 & St.5 \\
\hline 1 & Alpinia galanga & Lengkuas & 0,00 & 73,57 & 0,00 & 49,66 & 0,00 \\
\hline 2 & Amomum cardamomum & Kapulaga & 0,00 & 75,46 & 0,00 & 36,85 & 143,46 \\
\hline 3 & Costus speciosus & Pacing & 12,47 & 0,00 & 0,00 & 0,00 & 0,00 \\
\hline 4 & Curcuma aeruginosa & Temu ireng & 28,78 & 27,77 & 0,00 & 0,00 & 0,00 \\
\hline 5 & Curcuma domestica & Kunyit & 187,87 & 0,00 & 95,26 & 58,81 & 0,00 \\
\hline 6 & Curcuma petiolata & Temu badur & 0,00 & 0,00 & 44,85 & 0,00 & 0,00 \\
\hline 7 & Curcuma xanthorrhiza & Temulawak & 0,00 & 96,95 & 0,00 & 16,83 & 33,39 \\
\hline 8 & Kaempferia pandurata & Kunci & 14,28 & 0,00 & 31,15 & 0,00 & 0,00 \\
\hline 9 & Kaempferia rotunda & Kunir putih & 0,00 & 0,00 & 0,00 & 0,00 & 42,32 \\
\hline 10 & Zingiber americans & Lempunyang & 56,61 & 0,00 & 38,85 & 0,00 & 80,83 \\
\hline 11 & Zingiber cassumunar & Bengle & 0,00 & 0,00 & 25,20 & 10,94 & 0,00 \\
\hline 12 & Zingiber officinale & Jahe & 0,00 & 26,25 & 64,69 & 37,91 & 0,00 \\
\hline 13 & Zingiber officinale var. & Jahe emprit & 0,00 & 0,00 & 0,00 & 89,00 & 0,00 \\
& rubrum & Jumlah jenis & 5 & 5 & 6 & 7 & 4 \\
\hline
\end{tabular}

Dari tabel 2 terlihat bahwa di Kecamatan Sumowono ditemukan jumlah jenis paling banyak yaitu 7 jenis tumbuhan famili Zingebaraceae. Sebagian besar spesies yang ditemukan berada pada lahan budidaya. Selain itu ditemukan di pekarangan rumah, tumbuh liar di daerah bantaran sungai, dan lahan-lahan kosong. Spesies yang ditemukan di lahan budidaya umumnya ditanam secara tumpang sari dengan jumlah rumpun yang banyak.

Jenis tumbuhan famili Zingiberaceae di Kabupaten Semarang yang mendominasi dapat diketahui dari indeks nilai pentingnya yang disajikan pada Tabel 2. Jenis $C$. domestica (kunyit), Curcuma xanthorrhiza (temulawak) dan Amomum cardamomum (kapulaga) merupakan jenis-jenis tumbuhan yang ditemukan dengan nilai penting tinggi. Soegianto (1994) dalam Indriyanto (2006) indeks nilai penting adalah parameter kuantitatif yang dapat dipakai untuk menyatakan tingkat dominan (tingkat penguasaan) spesiesspesies dalam suatu komunitas tumbuhan.

Jenis kunyit ditemukan sangat melimpah di daerah Kecamatan Ungaran (stasiun 1) dan ditemukan cukup banyak di daerah Tengarang dan Sumowono. Tanaman jenis kunyit memang banyak dibudidayakan di Kabupaten Semarang dan bisa menambah sumber pendapatan masyarakat daerah tersebut. Menurut Direktorat Jendral Holtikultura (2006), Kabupaten Semarang merupakan daerah sentra kunyit. Faktor lingkungan yang mendukung menyebabkan jenis tanaman kunyit tumbuh melimpah di daerah 
tersebut. Menurut Muhlisah (1999), kunyit cocok ditanam di dataran rendah sampai dataran tinggi dengan ketinggian 2000 mdpl. Darwis, dkk (1991) menambahkan $C$. domestica ditanam secara tumpangsari dan memerlukan intensitas cahaya matahari secara penuh. Menurut Kuntorini (2005) kunyit merupakan tanaman yang penting dari famili Zingiberaceae karena memiliki banyak manfaat. Selain sebagai obat, masyarakat memanfaatkan kunyit sebagai bumbu masak, bahan obat dan minuman. Rimpang kunyit digunakan untuk melancarkan asi, obat luka, sakit perut, meningkatkan nafsu makan dan mempelancar persalinan. Manfaat kunyit yang banyak menyebabkan masyarakat cenderung membudidayakannya dari pada spesies dari famili Zingiberaceae lain.

Selain kunyit, jenis tumbuhan Zingeberaceae yang ditemukan dengan INP cukup tinggi adalah C. xanthorrhiza (temulawak). C. xanthorrhiza tumbuh secara liar dibantaran sungai dengan kondisi udara lembab. Menurut Direktorat Jendral

Tabel 3. Hasil rerata pengukuran faktor lingkungan pada stasiun penelitian
Holtikultura (2006), temulawak dapat tumbuh di dataran rendah sampai dataran tinggi. Kondisi lahan yang dibutuhkan adalah lahan yang terlindung oleh pohon-pohon dan suhu $19-30^{\circ} \mathrm{C}$. Dalam penelitian ini jenis temulawak dengan nilai tinggi ditemukan pada stasiun 2 (Kec. Bergas) dengan faktor lingkungan yang cocok untuk pertumbuhan jenis temulawak yaitu intensitas cahaya cukup rendah, suhu udara $25,4{ }^{\circ} \mathrm{C}$ (Tabel $3)$.

Jenis Amomum cardamomum (kapulaga) ditemukan melimpah di Kabupaten Semarang terutama di daerah Getasan. Jenis ini sebagian besar tumbuh liar. Menurut Darwis dkk (1991), kapulaga tumbuh secara liar di hutan-hutan dan membutuhkan kondisi yang lembab di bawah naungan pohon-pohon tinggi. Tempat ditemukannya kapulaga berada pada ketinggian lebih dari $1250 \mathrm{mdpl}$, intensitas cahaya 200-400 lux, kelembaban udara $89 \%$, suhu udara $24,4^{\circ} \mathrm{C}$ dan pH tanah 6,8 (Tabel 3).

\begin{tabular}{clllllc}
\hline \multirow{2}{*}{ No. } & Parameter & \multicolumn{5}{c}{ Stasiun } \\
\cline { 3 - 6 } & \multicolumn{1}{c}{ I } & II & III & IV & V \\
\hline 1 & $\begin{array}{l}\text { Ketinggian } \\
\text { Tempat }\end{array}$ & $<500$ & $500-750$ & $750-1000$ & $1000-1250$ & $>1250$ \\
\hline 2 & $\begin{array}{l}\text { Intensitas } \\
\text { Cahaya (lux) }\end{array}$ & $400-500$ & $250-750$ & $450-650$ & $650-950$ & $200-400$ \\
\hline 3 & $\begin{array}{l}\text { Kelembaban } \\
\text { Udara (\%) }\end{array}$ & 52,8 & 87,2 & 64 & 53,6 & 89,2 \\
\hline 4 & $\begin{array}{l}\text { Suhu Udara } \\
\left({ }^{\circ} \text { C) }\right.\end{array}$ & 30,6 & 25,4 & 26,6 & 27,6 & 24,4 \\
\hline 5 & $\begin{array}{l}\text { Suhu Tanah } \\
\left({ }^{\circ} \mathrm{C}\right)\end{array}$ & 29,8 & 24,4 & 26,4 & 26,3 & 20,2 \\
\hline 6 & pH Tanah & 6,8 & 5,6 & 5,6 & 5,3 & 6,8 \\
\hline
\end{tabular}

Keterangan: Rerata kecuali intensitas cahaya dan ketinggian tempat.

Menurut Direktorat Jendral Hortikultura (2006), Kabupaten Semarang merupakan salah satu kabupaten di Jawa Tengah yang berpotensi untuk pengembangan tanaman obat. Dari hasil penelitian ini ternyata masih ada beberapa jenis tumbuhan Zingeberaceae yang masih harus dikembangkan dan ditingkatkan budidayanya untuk bisa memproduksi tanaman obat sehingga kebutuhan akan tanaman obat bisa tercukupi.

\section{Distribusi Famili Zingiberacae di Kabupaten Semarang.}

Distribusi jenis tumbuhan dari famili Zingiberaceae di Kabupaten Semarang dapat diketahui dengan melihat derajat konstansinya yang disajikan dalam histogram Gambar 1. Menurut Dombois and Ellenberg (1974), derajat konstansi (DK) merupakan suatu ukuran yang dapat digunakan untuk mengetahui besarnya distribusi suatu jenis tumbuhan. Nilai derajat konstansi diperoleh dari perbandingan kehadiran 


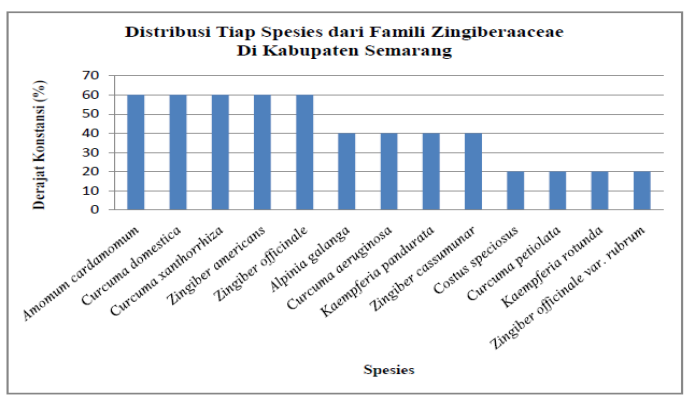

Gb. 1. Derajad Konstansi jenis-jenis tumbuhan famili Zingereraceae

Faktor lingkungan sangat menentukan distribusi dan pertumbuhan populasi suatu organisme. Spesies yang mempunyai distribusi paling luas dibanding spesies yang lain di Kabupaten Semarang adalah A. cardomomum, $C$. domestica, C. xanthorrhiza, Z. americans dan Z. officinale (DK: 60\%). Menurut klasifikasi nilai DK, kelima spesies tersebut termasuk dalam katagori distribusi sedang Dombois and Ellenberg (1974). A. cardomomum, Z. americans dan C. xanthorrhiza merupakan spesies yang tumbuh liar di bawah naungan pohon-pohon besar dan sering ditemukan di hutan-hutan. Spesies lainnya seperti C. domestica dan Z. officinale merupakan tanaman budidaya yang membutuhkan kondisi lingkungan yang terbuka (Darwis dkk, 1991).

Spesies yang mempunyai distribusi sempit dengan nilai DK $40 \%$ yaitu A. galanga, $C$. aeruginosa, $K$. pandurata dan $Z$. cassumunar. Spesies yang termasuk katagori distribusi jarang yaitu $C$. speciosus, C. petiolata, K. rotunda dan $Z$. officinale var rubrum (DK: 20\%). Dari hasil penelitian terlihat bahwa jenis tumbuhan familia Zingeberaceae ada yang merupakan tanaman budidaya dan ada jenis tanaman liar. Jenis-jenis yang melimpah merupakan tanaman yang sengaja dibudidayakan karena bisa menambah pendapatan masyarakat. Namun jenis-jenis ini tidak bisa ditemukan di seluruh daerah Kabupaten Semarang mengingat faktor lingkungan yang berbeda dan minat masyarakat terhadap budidaya tumbuhan jenis Zingeberaceae yang berbeda pula.
C. speciosus, C. petiolata, $K$. rotunda dan $Z$. officinale var rubrum memiliki distribusi jarang, masing-masing ditemukan di satu stasiun yang berbeda. Distribusi jarang dari spesies tersebut karena memerlukan lahan yang sesuai untuk pertumbuhannya dan memiliki manfaat lebih sedikit dari spesies lain.

Menurut Darwis dkk. (1991), C. speciosus memerlukan lahan yang memiliki naungan dengan intensitas cahaya sedang. $C$. petiolata dan $K$. rotunda memiliki distribusi yang jarang karena jarang dibudidayakan oleh masyarakat dan spesies ini hanya tumbuh liar. C. petiolata ditemukan tumbuh liar diladang. Menurut Kusmana (2010), C. petiolata merupakan tanaman obat yang dikatagorikan langka. Menurut Direktorat Budidaya Tanaman Sayuran dan Biofarmaka (2006), Z. officinale var rubrum memerlukan curah hujan 1500-3000mm per tahun. Menurut Badan Pusat Statistik (2009), curah hujan di Kecamatan Sumowono $2157 \mathrm{~mm}$ per tahun. Kondisi lingkungan di Kecamatan Sumowono tersebut cocok untuk membudidayakan $Z$. officinale var rubrum.

\section{KESIMPULAN}

Dari penelitian yang telah dilakukan dapat disimpulkan:

1. Di Kabupaten Semarang ditemukan 12 jenis tumbuhan dan satu varietas.

2. Jenis tumbuhan famili Zingiberaceae yang dominan di Kabupaten Semarang adalah Curcuma domestica, dan Amomum cardomomum.

3. Spesies yang terdistribusi paling luas di Kabupaten Semarang adalah Amomum cardomomum, Curcuma xanthorrhiza, Curcuma domestica, Zingiber americans dan Zingiber officinale.

\section{DAFTAR PUSTAKA}

Backer, C. A. and Brink, R. C. B. V. D. 1968. Flora of Java (Spermatophyta Only) Volume III. Wolters-Noordhoff N.V. Gronngen.

Badan Pusat Statistik. 2009. Kabupaten Semarang Dalam Angka Tahun 2009.

Delin, W. and Larsen K. 2000. Zingiberaceae. Flora of China 24:322-377. 
Darwis, S.N., Madjondo, A.B.D., Hasiyah, S. 1991. Tanaman Obat Famili Zingiberaceae. Badan Penelitian Dan Pengembangan Penelitian Pusat Penelitian dan Pengembangan Tanaman Industri. Bogor.

Direktorat Jendral Hortikultura. 2006. Profil Sentra Produksi Temulawak (Curcuma Xanthorrhiza Roxb). Direktorat Jendral Hortikultura, Direktorat Budidaya Tanaman Sayur dan Biofarmaka. .

Dumbois, D.M. and Ellenberg, H. 1974. Aim and Method of Vegetation Ecology. John Willey and Sons, Inc. New York

Heyne, K. 1987. Tumbuhan Berguna Indoneia: Jilid I-III. Yayasan Sarana Wana Jaya. Jakarta..

Indriyanto. 2006. Ekologi Hutan. Bumi Aksara. Jakarta.

Joy, P. P.,Thomas J.,Mathew, S., dan Skaria, B. B. 1998. Zingiberaceae Medicinal and Aromatic Plants. Aromatic and Medicinal Plants Research Station, Odakkali, Asamannoor P.Q., Kerala. India.

Kuntorini, E.M. 2005. Botani Ekonomi Suku Zingeberaceae Sebagai Obat Tradisional oleh Masyarakat di Kotamadya Banjarbaru Bioscientiae Volume 2 Nomor 2 Halaman 25-36.

Kusmana, C. 2010. Potensi Flora Indonesia

Muhlisah, F. 1999. Temu-temuan dan Emponemponan Budidaya dan Manfaatnya. Kanisius. Yogyakarta.

Odum. E. P. 1983. Basic Ecology . Saunders Collage Publishing. New York

Pandey, B. P. 2003. A Textbook of Botany: Angiosperm First Edition. S Chand and Company Ltd. New Delhi

Poernamasari,R. N. H. 1989. Distribusi dan Diversitas Gulma pada Pertanaman Kacang Tanah dan Jagung serta pada Pola Tanam Tumpang Sari. Skripsi. Fakultas Biologi Universitas Jenderal Soedirman Purwokerto. Purwokerto.

Siagian, S. 2009. Inventarisasi Zingiberaceae di Kawasan Agrowisata Hutan Taman Eden 100 Kabupaten Toba Samosir Sumatra Utara. Skripsi. Departemen Biologi Fakultas Matematika dan Ilmu Pengetahuan Alam Universitas Sumatra Utara. Medan. 